\title{
Design of a bed load and driftwood filtering dam, analysis of the phenomena and hydraulic design
}

\author{
M. Bianco-Riccioz \& P. Bianco \\ IDEALP SA, Sion, Switzerland \\ G. De Cesare \\ EPFL-LCH, Lausanne, Switzerland
}

\begin{abstract}
Flood protection often calls on to the realization of retention works for bed load as well as wood and debris flow. Certain relatively recent arrangements did not perform according to their intended function, what shows the complexity of the design and the implementation of such works. Adaptations were necessary to reach the security objectives.

The design of a retention dam for solid materials and floating driftwood requires the consideration of numerous hydraulic and material transport processes. The analyses and design validation can be made with two approaches: physical modelling by the construction of a reduced scale model and the test realization or numerical simulation, by means of software packages such as GESMAT (1D) or TOPOFLOW (2D). The present work consists in implementing both approaches, in estimating and in comparing the answers which could be given for a bed load and debris flow filtering dam on a river with a slope of the order of $10 \%$.

Thanks to water level gauges and visual observations during tests on the physical model, the progression of the obstructions by driftwood and bed load is well understood, and the effectiveness of these obstructions proven. The tested work plays at first a role of filtering and retention and secondly a role of side overflow towards a zone with low damage potential, when the capacity of the in-stream retention space is reached.

The performed numerical simulations, essentially in 1D, reproduce well the phenomena of bed load aggradation. Moreover, the potential obstruction by floating wood is considered and influences the behavior of the structure.

By putting in parallel physical and numerical models, it was possible thanks to the results from the physical scale model to refine the numerical simulation tools taking into consideration additional components and behavior-type rules. These further established rules can now be used for other cases where physical modelling is not foreseen.
\end{abstract}

\section{INTRODUCTION}

The issue of flood retention, the control of floating driftwood and bed load transport in an alpine environment is an important topic in the field of torrential hydraulics. Flood hazard maps exist and indicate the habitations threatened by flooding. In these threatened zones, there is a corresponding risk, more or less important, of loss of human lives. There is thus an absolute necessity to reduce the danger to a level judged acceptable.

In an alpine environment, the phenomena of the bed load transport play an important, even dominant, role in the determination and the establishment of flood hazard maps. Indeed, houses and other infrastructures in connection with human activities are often located on alluvial cones where the slope diminishes and where bed load transported by the torrent has thus the tendency to accumulate. This accumulation of solid materials 
leads to a decrease of the hydraulic capacity of the channel which results in a greater flood risk.

The necessity of designing structures which allow for the retention and/or the filtering of transported sediment and driftwood is evident. These works allow for avoiding a decrease or loss of the hydraulic capacity of the channel caused by excessive sediment deposits, by obstruction of bridges or by clogging of the channel due to driftwood.

Tests on a physical model together with numerical simulations of a real case, i.e. an alpine torrent in central Valais, Switzerland, with a slope of approximately $10 \%$ allowed (a) the evaluation of its functioning, (b) the proposition of alternative structural dimensions as well as (c) recommendations for the implementation and the optimization of this type of hydraulic work.

The tests on a physical model allowed for numerous analyses of the behaviour and the possibilities to build such a structure. The effect of driftwood could be well highlighted and rules were established and used for the numerical modelling.

The numerical simulations permitted to reproduce the functioning of the structure and allowed for adjustments. The solid and liquid flow behaviour were identified and quantified. The numerical simulation take into account the phenomena of obstructions by driftwood, their occurrence and time evolution as well as the conditions in which they occur. The GESMAT simulation program could in this way be extended by new hydraulic components.

\section{OBJECTIVES}

A retention structure for solid and liquid flows was planned to improve the flood safety on an alluvial fan, where the torrent slope varies between 6 and $9 \%$. Based on the project of a filtering dam, the present work consisted of carrying out the physical model tests, as well as one-dimensional and two-dimensional numerical simulations using IDEALP in-house software packages.

The objectives are the evaluation of the functioning of a "slit filter dam", the proposition of different geometries and dimensions as well as recommendations for the realisation and the optimisation of this type of structure. The physical and numerical models should be able to highlight the uncertainties as well as the adequacy of the different methods used in the predesign phase.

The main objectives of the study are the comprehension of the encountered phenomena as well as the hydraulic dimensioning of the various elements of the filtering dam, based on the analysis of the numerical and physical model test results. This study allows engineers to recognize the value of the different analysis and calculation tools.

There are many elements of the filtering dam to be conceived, designed and tested regarding their functioning:

- Bottom outlet which allows regular floods to pass

- Vertically arranged openings generally equipped with lateral beams made out of steal

- Adequate spacing of the lateral beams of the openings

- Overflow spillway on the top of the dam

- Stilling basin at the downstream end of the spillway

- Side spillway to evacuate the case of flood overload occurrence and to divert the discharge towards an additional retention space with a low damage potential.

The main questions that arise are:

- The time of obstruction of the bottom outlet

- The lateral overflow of water, debris and bed load in case of

1. The influx retention volume is full and/or

2. The trash rack is obstructed with driftwood and/or

3. The overflow spillway capacity is exceeded

- The quantities of water, debris and bed load that still transit downstream. 


\section{PHYSICAL MODELLING}

\subsection{Type and scale of the model}

The extent of the study zone covers an area of $150 \mathrm{~m}$ by $350 \mathrm{~m}$ at prototype scale, which corresponds at the physical model scale to approximately $5 \mathrm{~m}$ by $12 \mathrm{~m}$, built directly at natural ground level with corresponding slope next to a vineyard.

The physical model is built at the geometrical scale of 1:30. It is operated respecting Froude similarity, by admitting the preservation of the ratio between inertia and gravity forces. Figures 1 and 2 give an idea of the configuration of the physical model structure and its various components.

\subsection{Components of the model}

\subsubsection{Floating debris screen}

A floating debris screen situated upstream of the overflow dam allows for the retention of driftwood and favor sediment deposit in the influx retention space.

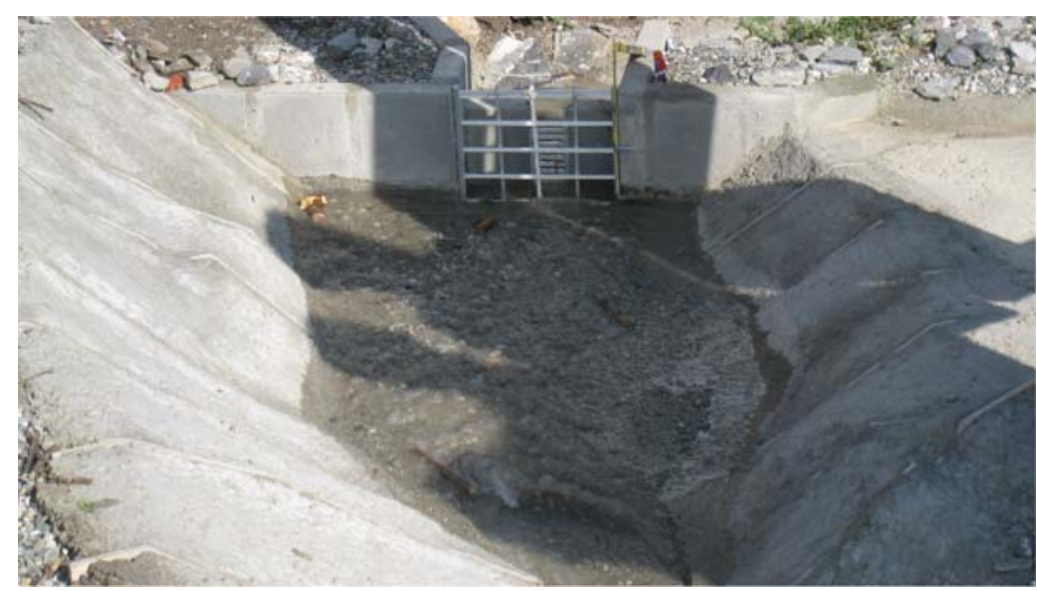

Figure 1. Physical model of the filtering dam with retention zone, view from upstream.

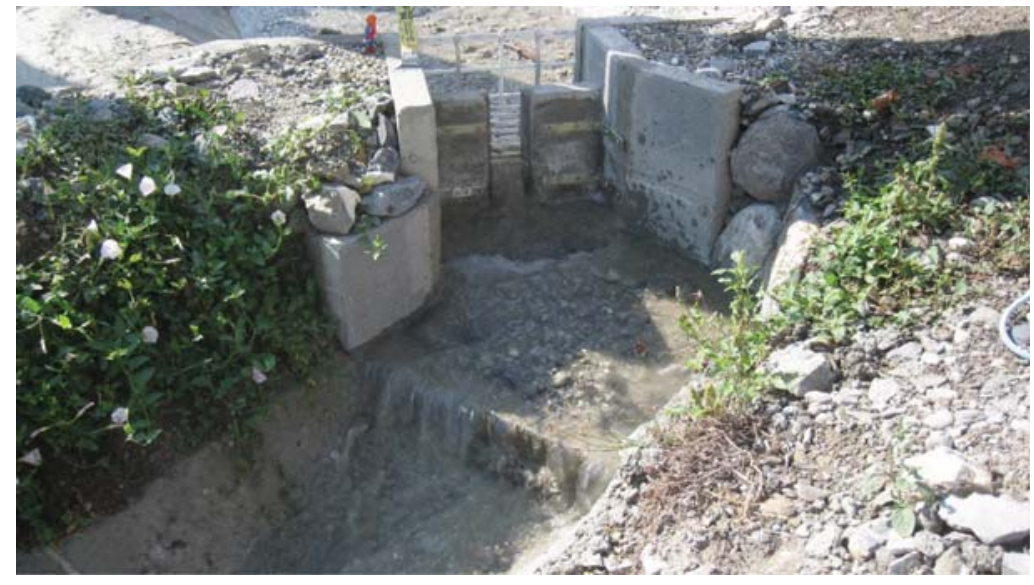

Figure 2. Physical model of the filtering dam with stilling basin, view from downstream. 
One of the objectives is to determine the best configuration that retains the driftwood without totally blocking the trash rack and not leading rapidly to the case of lateral flood overload. Lateral flood overload should not occur before reaching a flood event with a 100 -year return period.

\subsubsection{Orifice}

The narrowing of the flow section, with the bottom outlet and the transversal bars across the opening, provokes a backwater effect that is necessary to retain sediments, in particular in case of floods with few floating wood.

The bottom opening and the spaces between the lateral beams can be blocked by the floating debris that manage to cross the trash rack.

\subsubsection{Overflow spillway on the top of the dam}

When the water level reaches the level of the dam, the overflow spillway is activated.

Generally, the overflow spillway as well as the remaining opening has to allow for the transition of the entire discharge downstream without the risk of erosion nor the risk of dam failure.

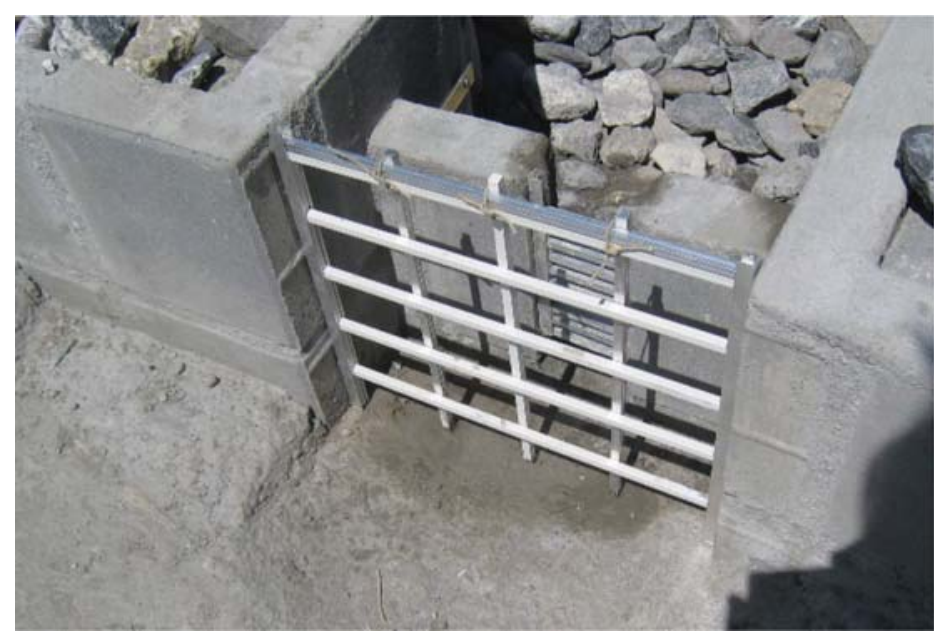

Figure 3. Floating debris screen installed in the physical model.

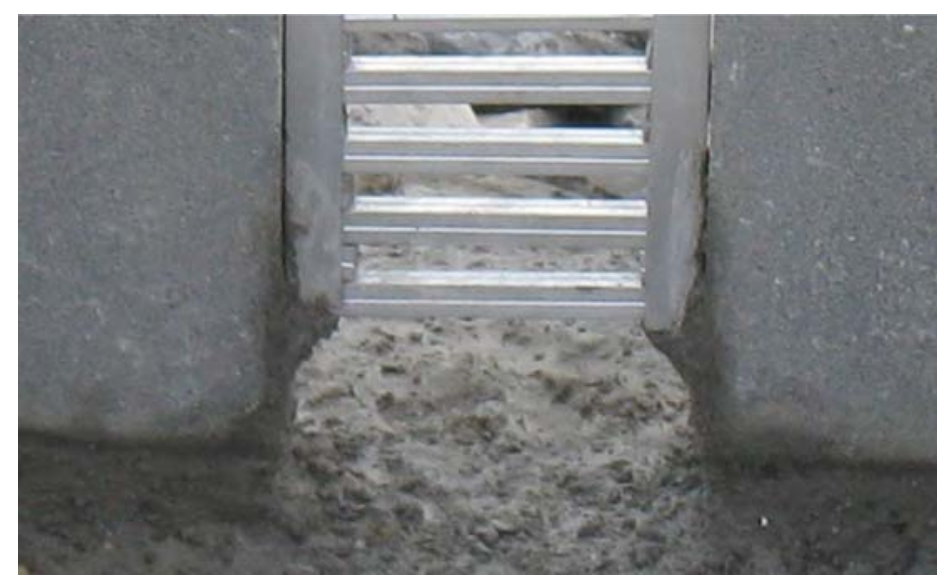

Figure 4. Bottom opening and upper flow section with horizontal beams on the physical model. 


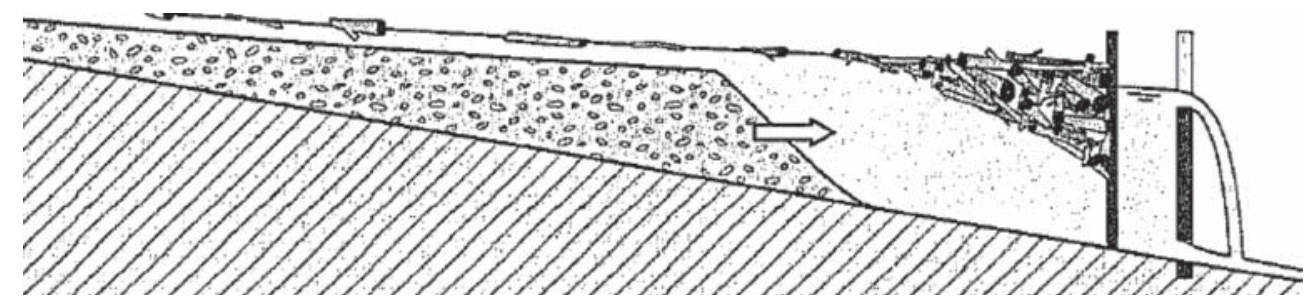

Figure 5. Overflow and gradual deposition of bed load and driftwood retention during an important flood event.

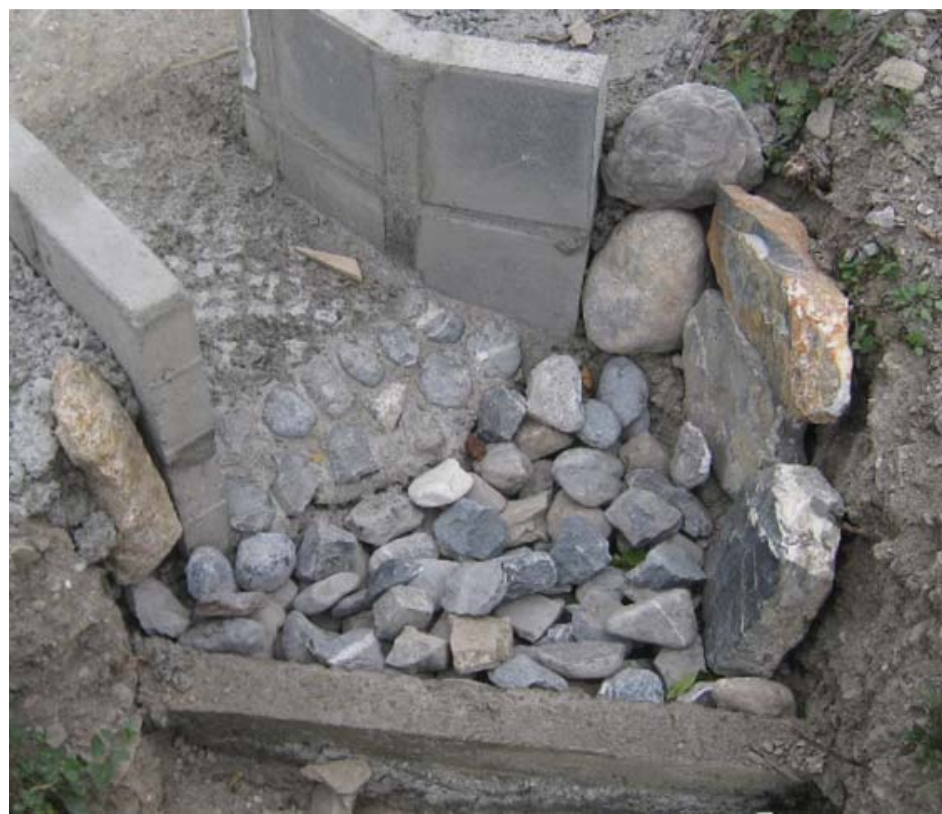

Figure 6. Stilling basin and downstream sill of the physical model.

If there is a possibility of lateral overflow, as it is the case in the studied configuration, this side overflow prevents the uncontrolled flooding of the dam and plays the role of a safety work reducing further the risk of erosion or dam failure.

\subsubsection{Stilling basin}

Downstream of the spillway, the stilling basin dissipates the flow energy. It is made of reinforced rockfill at its upper limit, then of a double layer of large-dimension freestanding blocks. This stilling basin is limited downstream by a sill at the level of the existing river bed. It ensures the safe transition of the flood discharge through the orifice and over the spillway, the dissipation of the energy and prevents erosions of the dam toe.

The geometry of the stilling basin and the height of the downstream sill permit additional filtering of bed load materials. In case of excess bed load transport, the sediment deposits create a reduced longitudinal slope that blocks the bottom opening and improves the retention conditions upstream of the dam.

\subsubsection{Lateral overflow}

For rare floods up to extreme events, according to the planned configuration, after the retention basin formed by the natural river bed has filled up with sediment deposits to the same 
elevation of the right bank, side overflows will occur. The flow will then orientate towards a zone with a minor damage potential, which was converted into a zone for additional sediment deposits for this purpose.

\subsection{Simulations carried out}

Floods of various return periods were simulated in the physical model, i.e. 10-year, 30-year, 100 -year return periods and extreme flood events. All tests were performed by adding driftwood as well as solid materials, except for the 10-year-flood scenario.

\section{NUMERICAL SIMULATIONS}

\subsection{GESMAT model}

The GESMAT model is a one-dimensional (1D) hydraulic program modelling bed load transport by fractions and which has a quasi-stationary module (sequences of backwater curves) as well as a non-stationary module by solving the Saint-Venant shallow water equations. The program is designed for small slopes (inferior to one per mill) as well as for steep slopes (up to $20 \%$ ). It allows for the consideration of numerous hypotheses concerning the development of an armoring layer as well as the presence of different artificial structures.

The components of the filtering dam are implemented in terms of the outlet (i.e. orifices or culverts), lateral beams and overflow structures. The partial or total obstruction of the orifice can be controlled by defining the speed of obstruction. The program enabled the numerical simulations of scenarios that are identical to the ones used in the physical model.

\subsection{TOPOFLOW model}

The model TOPOFLOW is a two-dimensional (2D) hydraulic model with implemented modules for the calculation of the bed load transport. It also allows investigating a wide range of slopes and influences from artificial structures. Additionally, the application of a 2D model enables the observation of the evolution of the riverbed morphology as well as lateral overflow. Good agreement between the geometry of the calculated and measured deposits has been observed. However, the present article is limited to the detailed comparison of the onedimensional numerical model GESMAT and physical model.

\section{COMPARISON OF THE RESULTS}

\subsection{The 10-year-flood scenario (Q10)}

The 10-year scenario was carried out without adding driftwood. The discharges correspond to a constant flow of $8 \mathrm{~m}^{3} / \mathrm{s}$ over 55 minutes. The deposits in the upstream zone of the trash rack calculated by GESMAT $(1.10 \mathrm{~m})$ and the ones measured after the physical test $(1.20 \mathrm{~m})$ are quite similar. The bed load transport was reduced by the filter dam in the order of about $30 \%$ in both cases, the numerical simulation as well as the physical model.

\subsection{The 30-year-flood scenario (Q30)}

The 30-year scenario was carried out with adding driftwood. The discharges correspond to a constant flow of $16 \mathrm{~m}^{3} / \mathrm{s}$ over 55 minutes. The deposition height calculated by GESMAT $(3.60 \mathrm{~m})$ and the one measured after the physical test $(3.90 \mathrm{~m})$ are again comparable.

The bed load transport was reduced by the filter dam in the order of about $80 \%$ in both cases. The numerical model does not indicate sediment depositions at the bottom opening. 


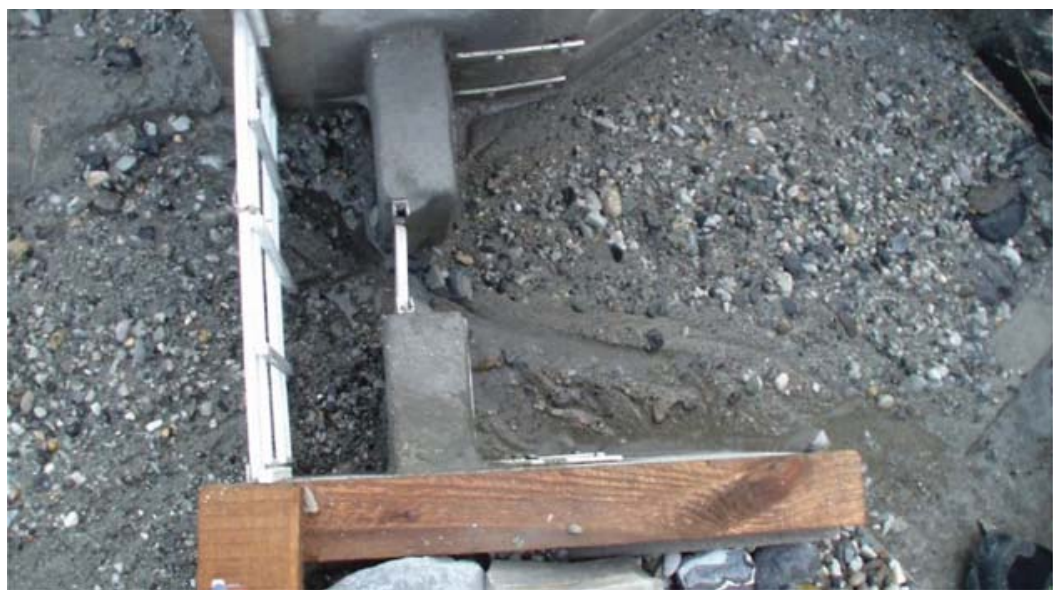

Figure 7. Situation at the dam after 10-year-flood event (physical model, flow from left to right).

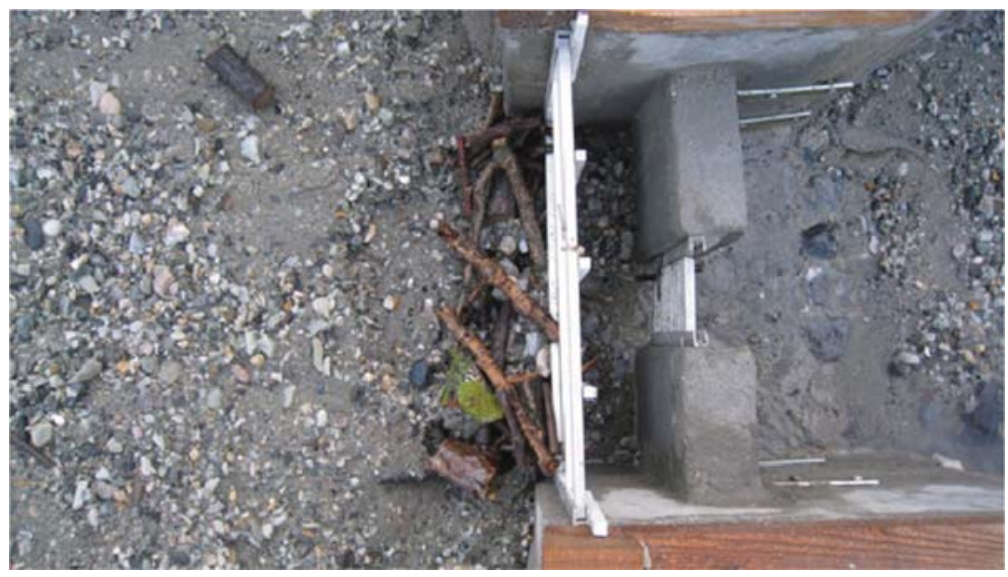

Figure 8. Situation at the dam after 30-year-flood event (physical model, flow from left to right).

This result was confirmed by the observations on the physical model where also no obstruction of the orifice had been observed.

\subsection{The 100-year-flood scenario (Q100)}

For the prototype, the peak discharges of a 100-year flood are about $30 \mathrm{~m}^{3} / \mathrm{s}$. The rising time is about 3 hours and the decreasing part takes about 6 hours. As indicated in Figure 9, the evolution of the riverbed calculated by GESMAT and measured after the test in the physical model are again alike.

The bottom outlet is blocked at the end of the test (Fig. 11). For the numerical model, the obstruction was defined by the opening between the lowest bar and the riverbed being inferior to $50 \mathrm{~cm}$. This corresponds to the diameter of the considerably largest driftwood trunks. Figure 10 shows the differences between the water levels of the numerical and the physical model. The agreement is good, even if the dynamics of the obstruction are not the same (scale effects). Indeed, at the end of the tests, the amount of stored sediments in front of the dam is the same. 


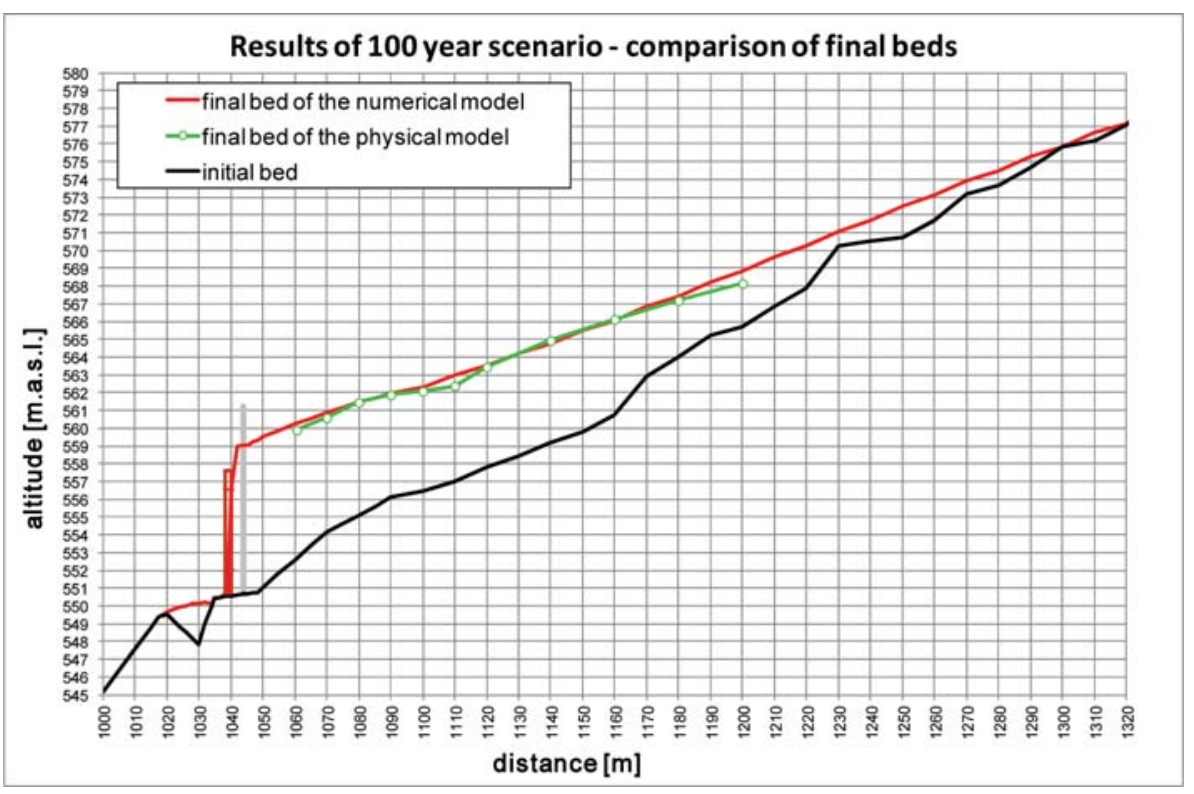

Figure 9. The 100-year-flood scenario-comparison of the sediment accumulation heights of the numerical and physical model along the thalweg.

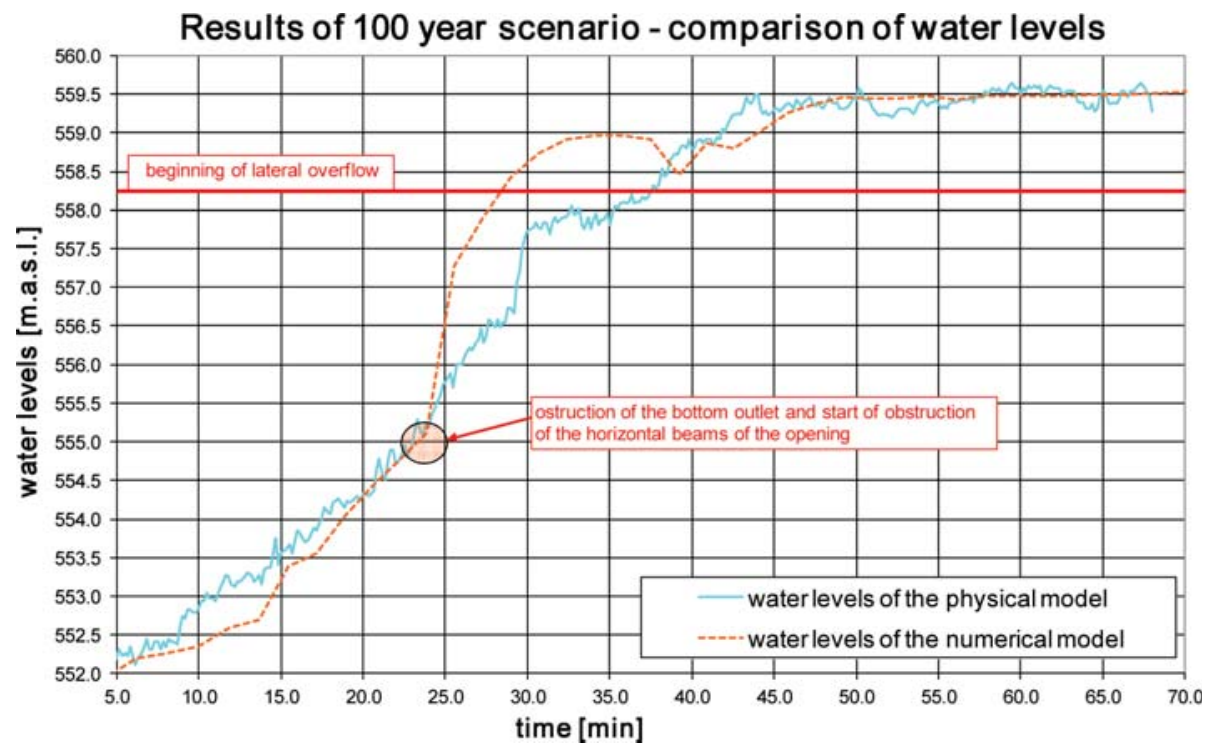

Figure 10. 100-year return period flood event - comparison of water levels for the physical and numerical model in function of time.

\section{SYNTHESIS}

The physical model reproduces reliably the bed load processes at slit filter dams, implicitly the clogging caused by driftwood. However, it cannot be used for each project. The numerical model reproduces properly the dynamic processes related to sediment transport, i.e. depositions in front of the dam and bed load transition towards the dam. Furthermore, the lateral 


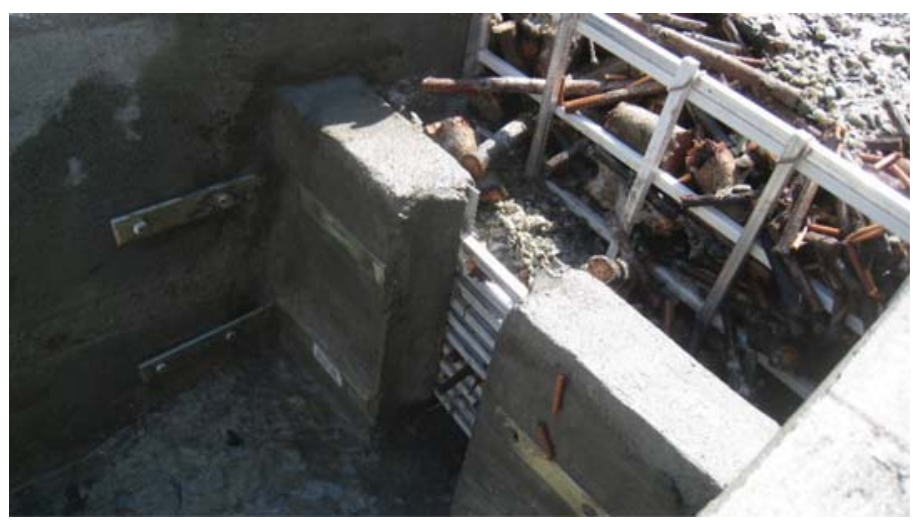

Figure 11. Situation at the dam after 100-year return period flood event on the physical model.

overflow of the dam can be evaluated pertinently. Thus, the numerical model allows for the investigation of different hydrological and obstruction scenarios in order to take into account variable site conditions. There is a good agreement between the results of the numerical and physical model for all tested scenarios. In conclusion, the bed load transport and driftwood accumulations at slit filter dams can be reproduced effectively using numerical models, such as GESMAT and TOPOFLOW.

\section{ACKNOWLEDGEMENT}

The project « Conception d'un barrage filtrant-Analyse des phénomènes et dimensionnement hydraulique » has been performed partially as a HES Bachelor work, it has been financially supported by CimArk Valais.

\section{REFERENCES}

De Cesare, G. (2010). Support de cours d'Hydraulique - hydrostatique, hydrodynamique, écoulements en charge, écoulements en nappe libre. Yverdon: HEIG-VD.

Fehr, R. (1987). Einfache Bestimmung der Korngrössenverteilung von Geschiebematerial mit Hilfe der Linienzahlanalyse. Schweizer Ingenieur und Architekt 105(38): 1104-1109.

Graf, W.H. and Altinakar, M.S. (2011). Hydraulique fluviale. Traité Génie Civil. Vol. 16. Lausanne: Presses Polytechniques et universitaires romandes.

Jäggi, M. (1995). Flussbau, Vorlesungsskript, ETH Zürich, Assistenz für Wasserbau.

Jäggi, M. (1992). Sedimentaushalt und Stabilität von Flussbauten. VAW Mitteilung 119, ETH Zürich.

Lencastre, A. (1995). Manuel d'hydraulique générale. Eyrolles, Paris, 633 pages.

Nussle, D. (2009), Bois flottants, processus, mesures d'aménagement hydraulique, Cours de formation continue "Protection contre les crues", 19/20 mars 2009 à Granges-Paccot, Association suisse pour l'aménagement des eaux et KOHS.

Rickenmann, D. (1997). Schwemmholz und Hochwasser. Wasser Energie Luft 89(5/6): 115-119.

Rickli, C. and Hess, (2009). Aspects de la formation des bois flottants, Cours de formation continue "Protection contre les crues", 19/20 mars 2009 à Granges-Paccot, Association suisse pour l'aménagement des eaux et KOHS.

Schleiss, A.J. (2008). Cours Aménagements Hydrauliques, Ecole polytechnique fédérale de Lausanne.

Sinniger R.O. and Hager W.H. (2008). Constructions Hydrauliques. Traité Génie Civil. Vol. 15. Lausanne: Presses Polytechniques et universitaires romandes. 